\title{
Evaluation of inclined crack in mixed modes I and II
}

\author{
Mohamed TaharHannachi* and Mohamed Bradji \\ Department of Mechanical Engineering, Larbi Tébessi University, Tébessa, 12000, Algeria. \\ * Corresponding Author: Mohamedtah334@gmail.com \\ $\begin{array}{ll}\text { Submitted } & : 02 / 04 / 2020 \\ \text { Revised } & : 25 / 06 / 2021 \\ \text { Accepted } & : 05 / 07 / 2021\end{array}$
}

\begin{abstract}
In this work, we tended to study the mixed mode of failure with two angles of inclination, of a treated steel. So, we tried to determine the parameters of failure as the stress intensity factor, tenacity, and the critical energy in mixed mode of a rupture and see the criterion of rupture and see the effect of the angles evolution applied for all parameters. There is a fragile and less ductile rupture.
\end{abstract}

Keywords: Mixedmode; Energy; Angle; Deformation; Tenacity.

\section{INTRODUCTION}

The residual stresses are linked to the phenomena of diffusion with the substrate (formation of oxides of molecular volume different from that of metal). It is also a determining criterion for the behavior of a mechanically stressed surface. These residual stresses can be a compression after a cold shaping treatment, surface plastic deformation, after a thermal or thermo chemical treatment (Beranger et al., 1994; Benard et al., 2008; \& Marder, 2000). These stresses may also be of tension under poorly adapted machining conditions (e.g., severe grinding) or during welding and reloading operations involving strong thermal gradients. In this case, they will be rather unfavorable, in particular for the initiation of fatigue cracks (mechanical or thermal) in the hollows of the roughness patterns, areas where the mechanical stresses are concentrated. The work hardening creates in the most superficial areas a consolidation of the material. The surface is generally worn in a state of compression: it has in principle greater hardness and greater resistance to cracking. In other cases, surface hardening can induce structural transformations. The formation of deformation martensite on the surface of metastable austenitic steels is an effective hardening process. Indeed, the metallurgical phenomena caused by the diffusion of nitrogen towards the core of the parts induce an increase in the surface hardness and introduce residual compressive stresses, the effects of which are known to delay the initiation of cracks and slow their spread. Although the mechanical properties of cemented layers with different grain sizes and precipitates are identical, it seems interesting to study the influence of the mechanisms of propagation of cracks (Peng et al., 2008). 


\section{MATERIALS AND METHODS}

Steels alloyed with chromium-manganese are less resistant to overheating and have lower ductility compared to chrome-nickel steels. A small addition of titanium $(0.03 \%$ to $0.09 \%)$ to this steel gives after case hardening quenching income, a layer case hardened with high hardness $(60 \mathrm{HRC})$, very low quench penetration. Thus, low addition of molybdenum increases it and gives maximum surface hardness. Table 1 and Table 2 give consecutively the chemical composition and the mechanical properties of steel $(20 \mathrm{MnCr} 5)$. Describing the mechanical properties validated, although determined by the tensile test, these characteristics (Papazian et al., 1973) better reflect the formability of materials because they reflect two large plastic properties of metals. Regarding the mild steels used, the use of plates with a specific surface state gives them a good resistance to galling (Martin et al., 1976).

Table 1. Chemical composition of $20 \mathrm{MnCr} 5$.

\begin{tabular}{|l|l|l|r|r|r|}
\hline \% C & \% Mn & \% Cr & \% Si & \% S & \% P \\
\hline 0.19 & 1.153 & 1.039 & 0.178 & 0.020 & 0.010 \\
\hline
\end{tabular}

Table 2. Mechanical properties of $20 \mathrm{MnCr} 5$.

\begin{tabular}{|c|c|c|c|}
\hline $\begin{array}{c}\text { Thickness } \\
\mathbf{t}(\mathbf{m m})\end{array}$ & $\operatorname{Re}(\mathbf{M P a})$ & $\begin{array}{c}\mathbf{R m} \\
\mathbf{( M P a})\end{array}$ & $\begin{array}{c}\mathbf{A} \\
\mathbf{( \% )}\end{array}$ \\
\hline$>16 \leq 40$ & 660 & $915-12007$ & 9 \\
\hline
\end{tabular}

The inclined crack that inclined in the transverse direction in relation to the propagation direction is often accompanied deformations. Cracking manifests itself in the irreversible separation in two parts, called cleft lips, which introduces a discontinuity in the sense of displacement. Possible lip movements of each crack are combinations of two independent modes.

A steel contains a through crack located next to and facing the direction of the applied stress. So, we seek to determine the strain of the plaque rupture.

The failure criterion is a combination of modes I and II fashion, as follows:

$\left(\frac{K_{I}}{K_{I C}}\right)^{2}+\left(\frac{K_{I I}}{2 K_{I C}}\right)^{2}=1$

The stress intensity factor is

$K_{I}=\sigma \cos ^{2}(\beta) f\left(\frac{a^{*}}{w}\right) \sqrt{\pi a}$ 


$$
K_{I I}=\sigma \cos (\beta) \sin (\beta) f\left(\frac{a^{*}}{w}\right) \sqrt{\pi a}
$$

The projection of crack length in normal line is

$$
a^{*}=a \sin (\beta)
$$

$$
f\left(\frac{a^{*}}{w}\right)=\frac{1-0.5\left(\frac{a^{*}}{w}\right)+0.37\left(\frac{a^{*}}{w}\right)^{2}-0.044\left(\frac{a^{*}}{w}\right)^{3}}{\sqrt{1-\left(\frac{a^{*}}{w}\right)}}
$$

Using the stress field in the singular zone and the law of behavior elastic linear, we can connect the energy function of stress intensity factor by

- in plan stress

$$
G=\frac{K_{I}^{2}+K_{I I}^{2}}{E}
$$

- in plan strain

$$
G=\frac{K_{I}^{2}+K_{I I}^{2}}{1-v^{2}}
$$

- in elastic material

$$
G=J
$$

Irwin has shown that energy and energy-based approaches constraints are equivalent. Using the field of constraints in the zone law of linear elastic behaviour, it is possible to link the rate of energy return with stress intensity factors (Irwin 1957).

All of the analyses, for the mechanics of the rupture, are strictly valid isotropic materials, which behave in a perfectly linear manner, elastic. When there is a small amount of plastic deformation at the tip of the crack, the linear mechanical breakage (LEFM linear elastic fracture mechanics) gives good approximation of the behaviour of these materials.

The singularity of the stress field near the tip of a crack can also be studied through some storytelling integrals deduced from the conservation law energy (Eshelby, 1974). These integrals have the distinction of being equivalent 
to the energy return rates and to be independent of the chosen integration outline. Among the most well-known outlines is Rice's complete J (Rice, 1968).

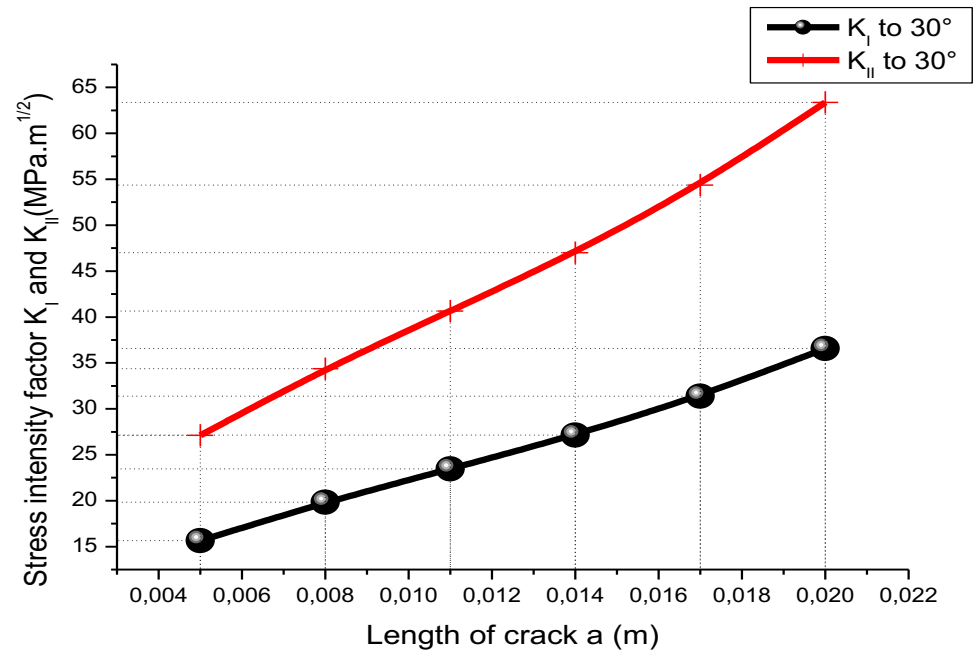

Figure 1. Stress intensity factors in mixed mode function of crack length at $30^{\circ}$.

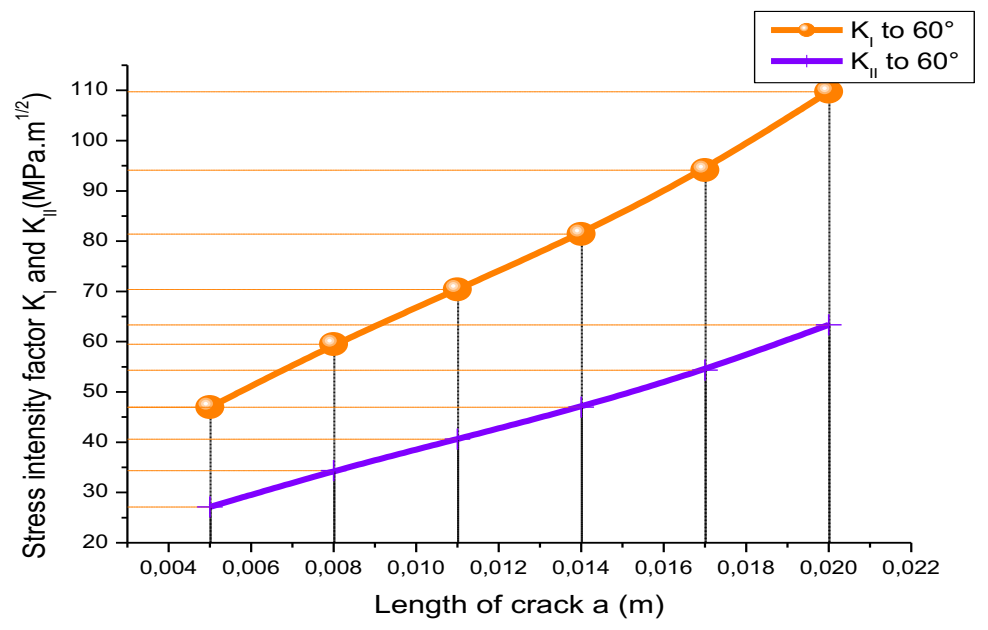

Figure 2. Stress intensity factors in mixed mode function of crack length at $60^{\circ}$. 


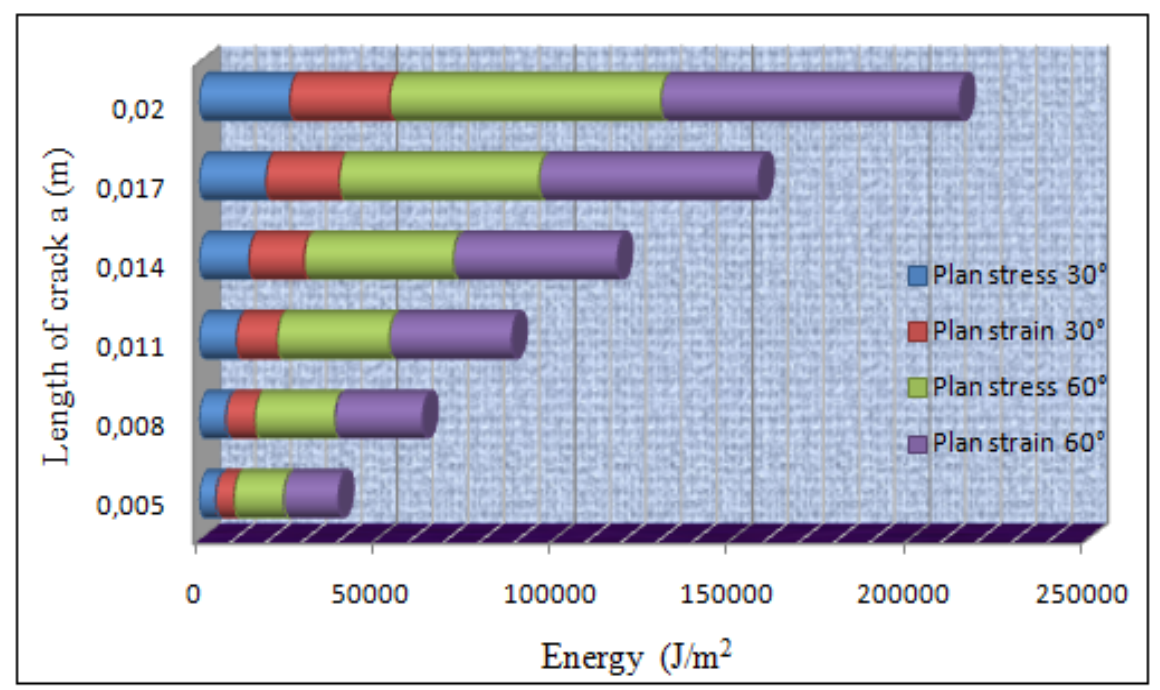

Figure 3. Density of energy function of crack length in to plan stress and strain and angles.

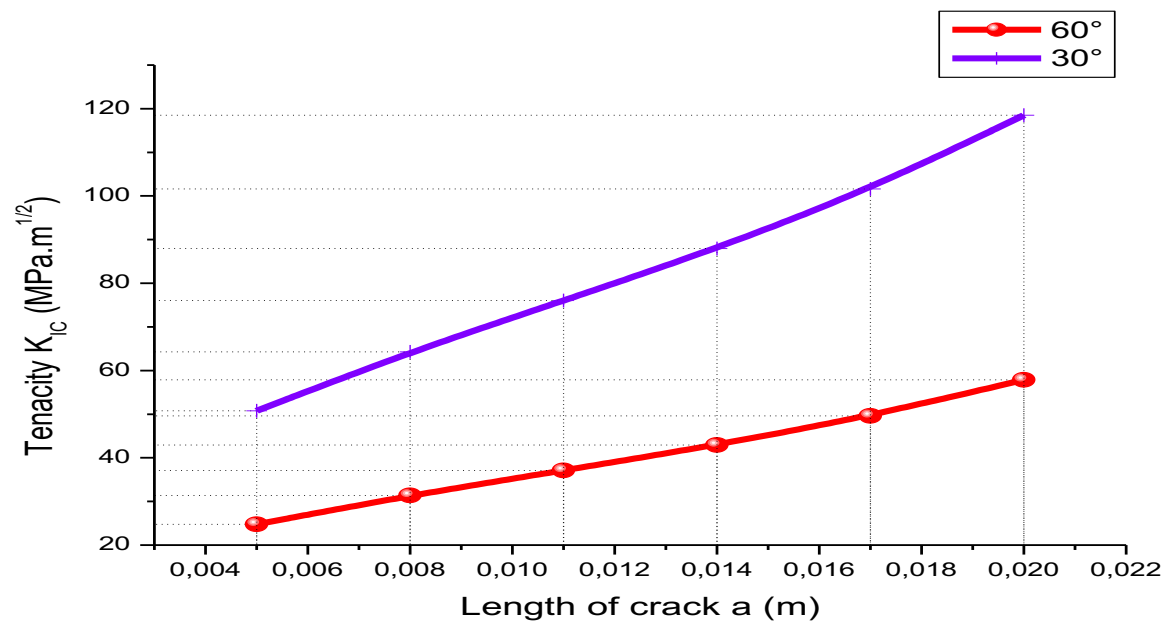

Figure 4.Variation of tenacity KIC function crack length at $30^{\circ}$ and $60^{\circ}$.

\section{MODELING AND ANALYSIS}

Modeling discontinuities are always a challenge from a numerical point of view. If cracks are to be modeled using the classic finished elements (MEF) method, the mesh must conform with the geometry of the crack. In addition, in order to determine the true field of stress and deformation around the tip of the crack, we need to refine the mesh in this area. Manufacturers demonstrate the need for modeling tools and/or simulation by castem3M, methodological and predictive, to improve the reliability of calculate. A key challenge for development teams of crack structure lies in predicting the mechanical effects of loading (stresses and deformation). For this reason, the numerical method to describe the behavior of a structure at the point of resistance is therefore the finite element method (Lefichoux, 2000). The program allows us to obtain the following: 
- a single edge (symmetric) crack specimens with inclined $2 \mathrm{D}$ (see ;

- the deformation is shown at different amplitudes (see Figure 6);

- the Von Mises stresses (see ;

- the plastic zone after deformation ( see Figure 8).
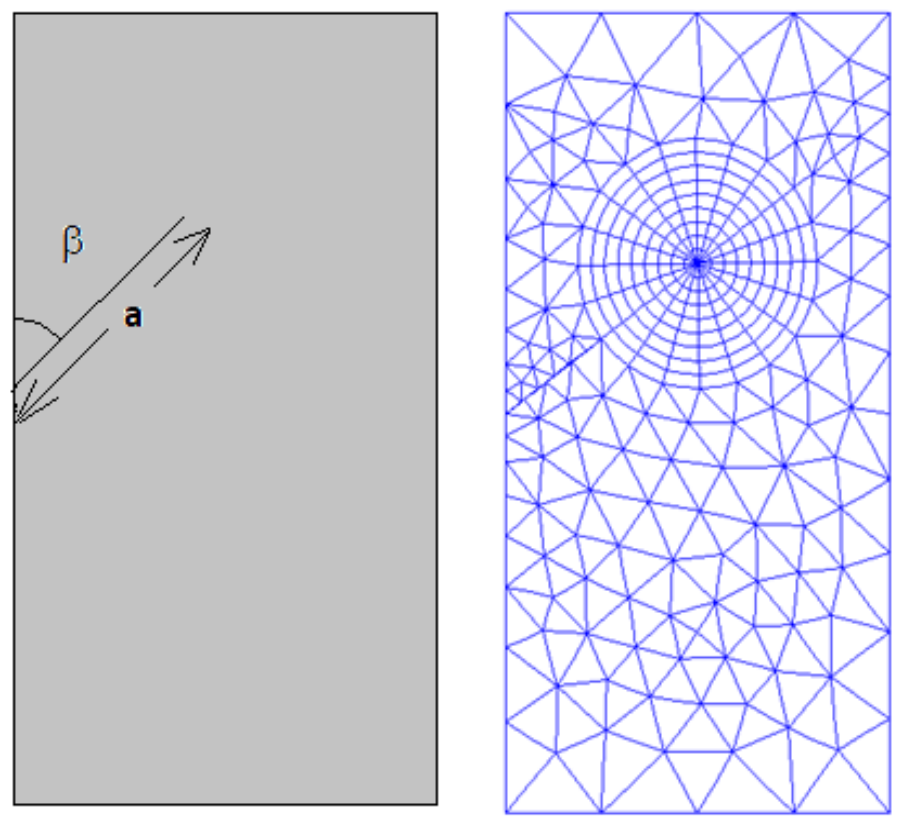

Figure 5. 2D Simulation of inclined crack.
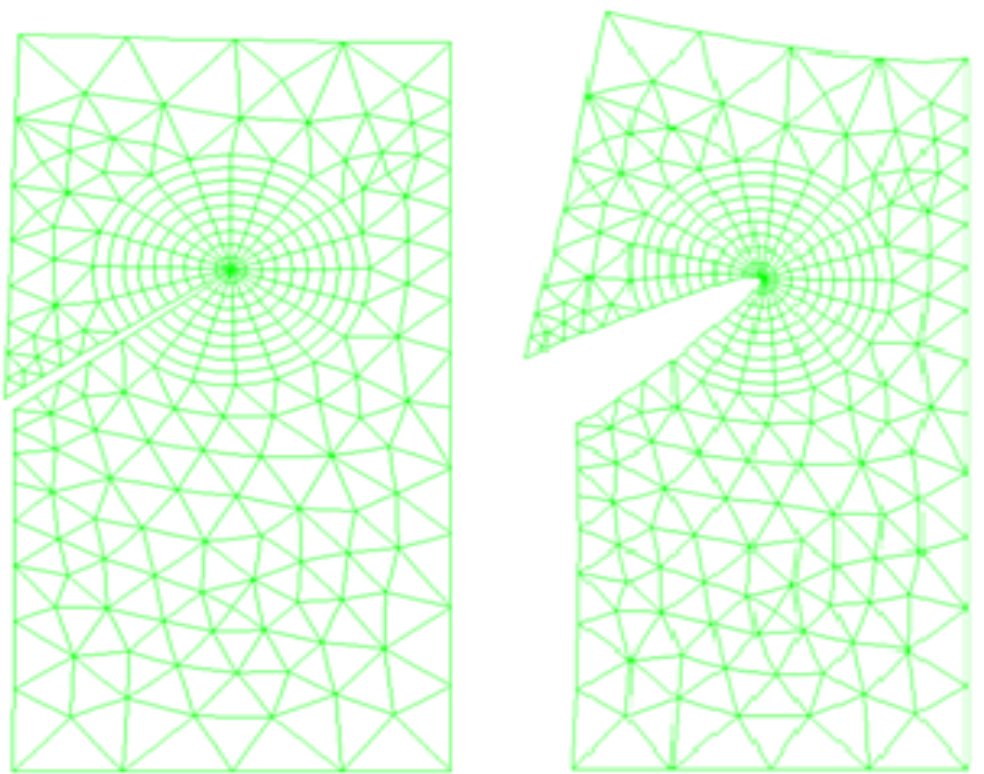

Figure 6. Deformation after loading. 

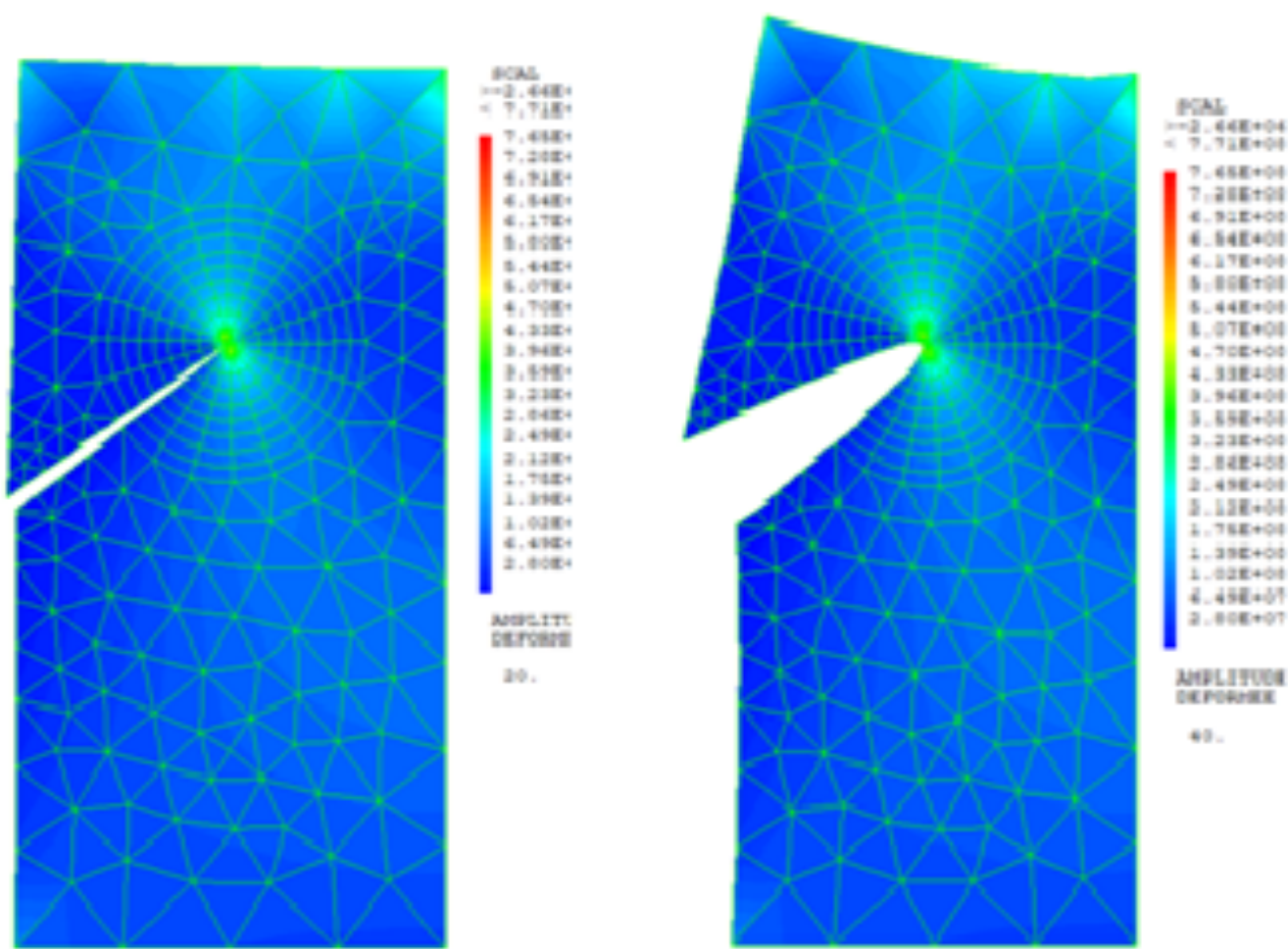

7. $658+04$

7. anetial

c. $-225+04$

cinetiont

S. Inetil

S. $446+04$

1. $075+04$

S-7ectot

C.-3atedit

$-946004$

$3.62+34$

9.

2. 4 seted

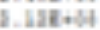

i. $75 x+94$

instoit

$4-4 \sin 40$

vosert

10. Notirioca

เ.

Figure 7. Von Mises stresses after deformation.
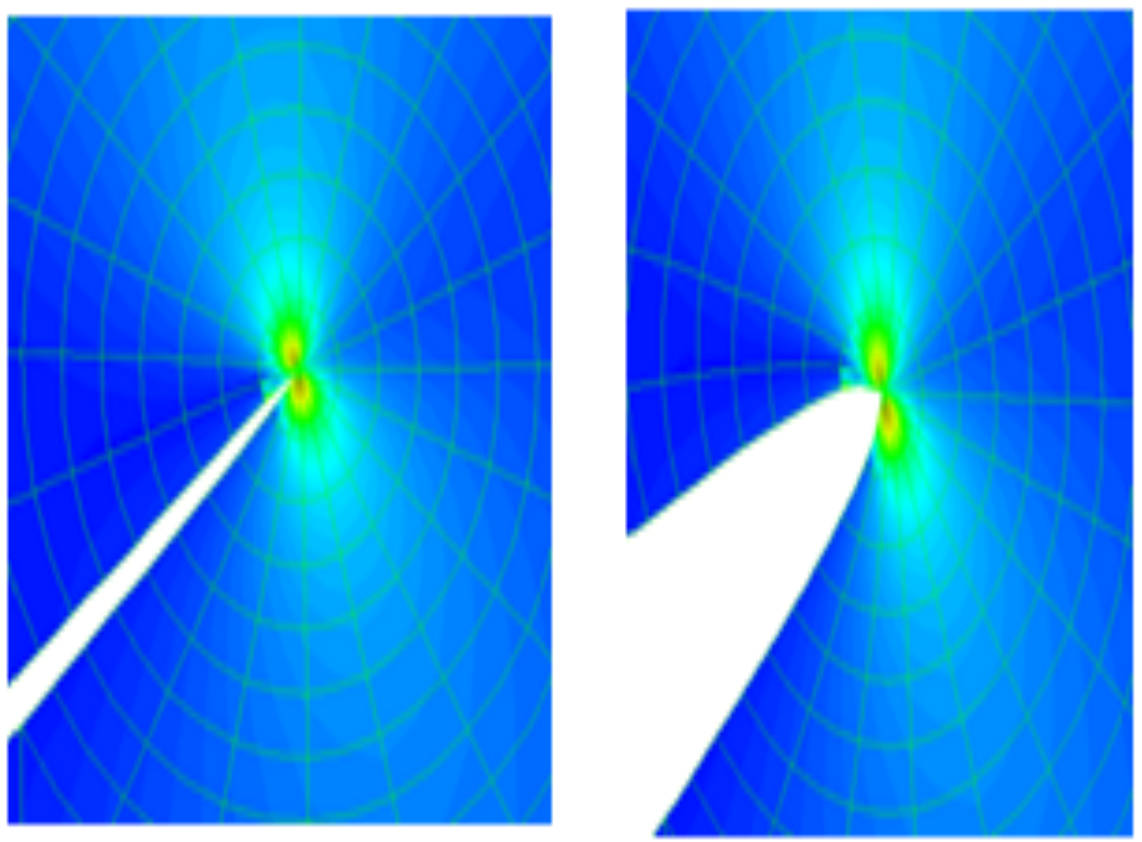

Figure 8. Plastic zone after deformation. 


\section{DISCUSSION OF RESULTS}

The comparison of the stress intensity factors in mixed mode $\left(\mathrm{K}_{\mathrm{I}}\right.$ and $\mathrm{K}_{\mathrm{II}}$ presents results for the variation loading, respectively, and compares the proposed model, calculating the studies in the open literature. We tested specimens and varied the loading angle, to produce mixed modes I-II loading condition. Compared with these cases, the crack inclination angles $\left(30^{\circ}\right.$ and $60^{\circ}$ degrees) and the load are multiplied by cos and sin for $\mathrm{K}_{\mathrm{I}}$ and $\mathrm{K}_{\mathrm{II}}$, respectively. The abscissa represents the crack inclination angle for the current study and the loading angle. The present model is compared for one different value of the applied loads (500 MPa) as considered in the simulation and calculus. A value of angle of inclination $\left(30^{\circ}\right)$ gives the excess value of $\mathrm{K}_{\mathrm{II}}$ and the reverse for the angle $\left(60^{\circ}\right)$, where KI dominates (see Figure 1 and Figure 2). $\mathrm{K}_{\mathrm{II}}$ is same for angles $\left(30^{\circ}\right.$ and $\left.60^{\circ}\right)$. This essentially returns to the equality of the cos and sin functions for this angle, see Figure 1 and Figure 2.

The observation recorded in Figure 3 represents the evolution of density of energy, already used by Griffith, (Griffith, 1920), but it is placed in a more general framework of study, the crack with the two angles $\left(30^{\circ}\right.$ and $\left.60^{\circ}\right)$, when the value of plan strain is bigger than plan stress.

According to the failure criteria $\left(\mathrm{K}_{\mathrm{I}}=\mathrm{K}_{\mathrm{IC}}\right)$, the fracture surface will therefore include a wide, brittle, planar ,and slightly ductile inclination fracture zone. The estimation of the mixed-mode is based on the formation of the overdetermined system of equations. The proposed method must be implemented in the existing finite element codes. We employed a model with finite element method to evaluate stress intensity factors and energy.

For the case of linear elastic material behavior, the strain energy density function can be expressed in the stress components and the material parameters $\mathrm{E}$ and $v$. At the crack tip, these stress components are known functions of $\mathrm{r}$, $\theta$, KI, and KII. The strain energy density factor is also known and dependent on $\theta$. KI, and KII, (Sih et al., 1973; Sih, 1973; and Sih, 1974).

After Loading the deformation increases, with loading deformation and crack edges open with increase in von stress (Figure 6 and Figure 7).

We observed that, for all examples, the size and shape of the plastic zones from finite element analyses depend on the combination of the nominal stress axial ratio and the angle of crack length inclination (Shlyannikovin, 2003; Shlyannikov, 2010;Shlyannikov et al., 2010,;Shlyannikov et al., 2010; and Sih,1991). A comparison of the plastic strain distributions at the angle of inclination $\mathrm{a}=30^{\circ}$ with the ones for $\mathrm{a}=60^{\circ}$ clearly shows that only the equiaxial tension is invariant with respect to the crack angle for any point of the crack front, as it is expected from an analytical consideration of a mixed-mode problem.

\section{CONCLUSION}

In this work, we tempted to study the variation of the crack in modes I and mode II. The method is based on parameters of failure (the stress intensity factor, tenacity, and critical energy). Examining the effect of evolution of angles on parameters of cracks on mixed mode fatigue crack, the evolution of the crack length with tenacity and energy decreases with the increasing angle. For the development teams, crack structure lies in predicting the mechanical effects of loading (stresses and deformation). For this reason, the numerical method to describe the behavior of a structure at the point of resistance is therefore the finite element method.The program allows obtaining a single edge (symmetric) crack specimens with inclined $2 \mathrm{D}$. The deformation (strain) is shown at two amplitudes and the illustration of Von Mises stresses. 


\section{REFERENCES}

Beranger, G. \&Charbonnier, J.C. 1994. La notion de surface, 1994. Le livre de l'acier, Chapitre 20, DirecteursscientifiquesLibrairie Lavoisier: 506-531.

Benard, J., Michel, A., Philiber, T. J. \&Talbot, J. 2008.Métallurgiegénérale. Masson Édition, Paris : 409410.

Marder, A.R. 2000.The metallurgy of zinc coated steel, Prog Mater Science 45(3): 191-271.

PengBicao, Wang, J., Su Xuping, Li Z. \&Yin Fucheng2008. Effects of zinc bath temperature on the coatings of hot-dip galvanizing. Surface \& Coating Technology 202(9):1785-1788.

Papazian, L. \&Martin, R. 1973. Analysis of the formability of thin plates by the coef - cients of hardening and anisotropy. CETIM Inf. (F), 32: 34-7.

Martin, R., Papazian, L,.\&Ferron, A.1976. Properties of plastic hardening and anisotropy of metals. Application to the formability by drawing cold thin sheets. Memoirs Techn. CETIM (F) : 23.

Irwin, G.R. 1957. Analysis of the Stresses and Strains near the End of CrackTraversing a Plate. ASME J. Appl. Mech., 24(3): 361-364.

Eshelby, J.D. 1974. Calculation of energy release rate. In: Prospect of FractureMechanics Nordhoff, UK.:6984.

Rice, J.R. 1968.Path independent integral and the approximate analysis of strainconcentration by notches and cracks. Journal of Applied Mechanics, Transactions ASME.35 (2): 379-386.

Lefichoux, E.1998. Introduction and Use of CASTEM 2000; ENSTA-LME, (http ://www-cast3m.cea.fr): 3738.

Griffith, A. A. 1921. The phenomena of rupture and flow in solids. Phil. Trans. Roy. Soc. of London, A221: 163-197.

Sih, G.C., Chen E.P. 1973. Fracture analysis of unidirectional composites. J. of composite materials, Vol 7(2): 230-244

Sih, G.C. 1973. Handbook of stress intensity factors. Lehig University, Bethlehem, Pennsylvania 18055: 292 293

Sih, G.C. 1974. Strain-energy-density factor applied to mixed mode crack problems. Int. J. Fract. 10(3): 305322 .

Shlyannikov, V.N. 2003. Elastic-Plastic Mixed-Mode Fracture Criteria and Parameters. SpringerVerlag, Lecture Notes in Applied Mechanics, vol. 7: 1-72.

Shlyannikov, V.N. 2010. Fatigue crack path for inclined cracks and surface flaws under biaxial loading. Engineering Fracture Mechanics 77(11): 1772-1780.

Shlyannikov, V.N., Kislova, S.Yu.,\&Tumanov, A.V. 2010. Mode mixed parameters accounting for semielliptical surface crack behavior. In: Proceedings of the 18th European Conference Fracture, Dresden, Germany : 1-8.

Shlyannikov, V.N., Kislova, S.Yu. \&Tumanov, A.V. 2010. Inclined semi-elliptical crack for predicting crack growth direction based on apparent stress intensity factors. Theoretical and Applied Fracture Mechanics 53 (2): 185-193.

Sih, G.C.1991.A three-dimensional strain energy density factor theory of crack propagation, Mechanics of Fracture Initiation and Propagation, book series, Vol. 11: 23-56. 